\title{
Article \\ Structural Characterization of Daunomycin-Peptide Conjugates by Various Tandem Mass Spectrometric Techniques
}

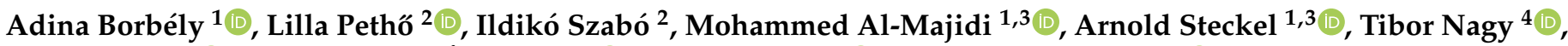

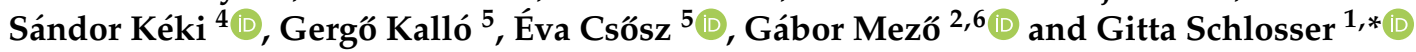

1 MTA-ELTE Lendület Ion Mobility Mass Spectrometry Research Group and Department of Analytical Chemistry, ELTE Eötvös Loránd University, Pázmány Péter sétány 1/A, H-1117 Budapest, Hungary; adina.borbely@outlook.com (A.B.); mohideenmoscow@gmail.com (M.A.-M.); starnold@caesar.elte.hu (A.S.)

2 Eötvös Loránd Research Network, Supported Research Groups, Research Group of Peptide Chemistry, Pázmány Péter sétány 1/A, H-1117 Budapest, Hungary; lilla.petho@chem.elte.hu (L.P.); szaboi8@gmail.com (I.S.); gmezo@caesar.elte.hu (G.M.)

3 Hevesy György PhD School of Chemistry, ELTE Eötvös Loránd University, Pázmány Péter sétány 1/A, H-1117 Budapest, Hungary

4 Department of Applied Chemistry, Faculty of Science and Technology, University of Debrecen, Egyetem tér 1, H-4032 Debrecen, Hungary; nagy.tibor@science.unideb.hu (T.N.); keki.sandor@science.unideb.hu (S.K.)

5 Proteomics Core Facility, Department of Biochemistry and Molecular Biology, Faculty of Medicine, University of Debrecen, Egyetem tér 1, H-4032 Debrecen, Hungary; kallo.gergo@med.unideb.hu (G.K.); cseva@med.unideb.hu (É.C.)

6 Department of Organic Chemistry, ELTE Eötvös Loránd University, Pázmány Péter sétány 1/A, H-1117 Budapest, Hungary

check for updates

Citation: Borbély, A.; Pethő, L.; Szabó, I.; Al-Majidi, M.; Steckel, A.; Nagy, T.; Kéki, S.; Kalló, G.; Csősz, É.; Mező, G.; et al. Structural

Characterization of

Daunomycin-Peptide Conjugates by Various Tandem Mass Spectrometric Techniques. Int. J. Mol. Sci. 2021, 22, 1648. https://doi.org/10.3390/ijms 22041648

Academic Editor: Laszlo Prokai

Received: 29 December 2020

Accepted: 3 February 2021

Published: 6 February 2021

Publisher's Note: MDPI stays neutral with regard to jurisdictional claims in published maps and institutional affiliations.

Copyright: (c) 2021 by the authors. Licensee MDPI, Basel, Switzerland. This article is an open access article distributed under the terms and conditions of the Creative Commons Attribution (CC BY) license (https:// creativecommons.org/licenses/by/ $4.0 /)$.
* Correspondence: schlosser@caesar.elte.hu; Tel.: +36-1-372-2500
Abstract: The use of peptide-drug conjugates has generated wide interest as targeted antitumor therapeutics. The anthracycline antibiotic, daunomycin, is a widely used anticancer agent and it is often conjugated to different tumor homing peptides. However, comprehensive analytical characterization of these conjugates via tandem mass spectrometry (MS/MS) is challenging due to the lability of the O-glycosidic bond and the appearance of MS/MS fragment ions with little structural information. Therefore, we aimed to investigate the optimal fragmentation conditions that suppress the prevalent dissociation of the anthracycline drug and provide good sequence coverage. In this study, we comprehensively compared the performance of common fragmentation techniques, such as higher energy collisional dissociation (HCD), electron transfer dissociation (ETD), electron-transfer higher energy collisional dissociation $(\mathrm{ETh} C \mathrm{D})$ and matrix-assisted laser desorption/ionizationtandem time-of-flight (MALDI-TOF/TOF) activation methods for the structural identification of synthetic daunomycin-peptide conjugates by high-resolution tandem mass spectrometry. Our results showed that peptide backbone fragmentation was inhibited by applying electron-based dissociation methods to conjugates, most possibly due to the "electron predator" effect of the daunomycin. We found that efficient HCD fragmentation was largely influenced by several factors, such as amino acid sequences, charge states and HCD energy. High energy HCD and MALDI-TOF/TOF combined with collision induced dissociation (CID) mode are the methods of choice to unambiguously assign the sequence, localize different conjugation sites and differentiate conjugate isomers.

Keywords: anthracyclines; bioconjugates; collision-induced dissociation; electron predator; high resolution mass spectrometry; MALDI

\section{Introduction}

In recent years, peptide-drug conjugates (PDCs) have become an effective approach for the targeted delivery of therapeutic agents [1]. In this strategy one or more chemotherapeutic agents are covalently attached to peptides which can serve as carriers to selectively deliver cytotoxic drugs to solid malignancies. PDCs aim to overcome the limitations of 
traditional chemotherapy and ensure high therapeutic efficacy with low toxic side effects, thereby improving the quality of life of patients receiving anticancer treatment. Hence, peptide-targeted drugs are promising tools for modern precision medicine [1-3].

The $\alpha$-melanocyte-stimulating hormone ( $\alpha$-MSH, Ac-SYSMEHFRWGKPV- $\mathrm{NH}_{2}$ ), the adrenocorticotropic hormone (ACTH, SYSMEHFRWGKPVGKKRRPVKVYPNGAEDESAE AFPLEF), and other related peptides are produced by the proteolytic cleavage of the polypeptide precursor proopiomelanocortin (POMC) [4]. Given that $\alpha$-MSH peptide analogs specifically bind to melanocortin-1 (MC1) receptors, they are promising drug carriers in melanoma therapy [5]. The analog containing Nle at position 4, as well as the central fragments containing lysine residues exhibit high melanotropic activity, thus providing a wide platform for PDC development with different sites for drug conjugation [6].

Over the last few years, our research group has intensively focused on the development of PDCs based on the anthracycline antitumor antibiotic, daunomycin (Dau). Daunomycin has been conjugated to several cancer-specific peptides and the biological properties of the resulting bioconjugates have been investigated in detail [7-9]. Several promising new compounds that exert strong in vivo antitumor effect are in preclinical development [10-12]. The comprehensive analytical characterization of drug candidates is not only a key step at various stages of drug development, but also a fundamental requirement of the regulatory authorities [13]. Tandem mass spectrometry (MS/MS) is an effective technique for providing extensive data that supports the structural identification of PDCs.

Significant spontaneous fragmentation of anthracycline containing conjugates during electrospray ionization (ESI) has a negative effect on the quality and reliability of the resulting ESI-MS data, thereby hindering the conduct of mass spectrometric analysis of these compounds $[14,15]$. Daunomycin consists of a tetracyclic quinoid aglycone and a daunosamine sugar moiety attached to the aglycon part through an O-glycosidic bond. Mass spectrometric analysis by ESI indicates that Dau produces a characteristic in-source fragmentation pattern. The main fragmentation pathway for daunomycin is the cleavage of the glycosidic bond, with the charge residing either on the aglycon part or on the sugar moiety, which co-occurs with secondary dissociation mechanisms for each fragment [16]. Furthermore, daunomycin conjugates also show extensive fragmentation under the standard ESI-MS workflow that uses slightly acidic solvents [14,17-19]. When the drug moiety is attached via oxime bond to the tumor targeting peptides, the cleavage of the sugar moiety from the daunomycin is the most prominent fragmentation pathway [14]. The same sugar loss fragmentation is pronounced during higher energy collision-induced dissociation (higher-energy C-trap dissociation, HCD) MS/MS analysis, thus suppressing the fragmentations of other types [15]. Consequently, MS and MS/MS analysis of daunomycinbioconjugates results in a complex spectrum containing a mixture of daunomycin related fragments, generally hampering unambiguous assignment, accurate purity estimation and definitive structural identification.

Different strategies, including the electron transfer dissociation (ETD) [20] and the electron transfer/higher energy collisional dissociation (EThcD) [21] are the most widely adopted fragmentation techniques often surpassing the sequence coverage of the HCD method. Thus, these methods hold great potential for enhanced characterization of peptidebased samples. Besides ESI, matrix-assisted laser desorption/ionization (MALDI) coupled to a tandem time-of-flight analyzer (TOF/TOF) can also provide highly sensitive peptide sequence information [22].

In the current study we focused on the structural identification of daunomycin-peptide conjugates using high resolution mass spectrometry and the above-mentioned MS/MS techniques aiming at high-coverage for the comprehensive characterization of PDCs. For this purpose, new daunomycin conjugates were synthesized containing $\alpha$-MSH analogs as tumor targeting peptides. To investigate the influence of structural elements on the fragmentation, targeting peptides of different lengths were used and daunomycin was conjugated either to the $\mathrm{N}$-terminus or to the lysine side chain of the peptides. We expected 
that the position of the daunomycin in structural isomers might lead to distinct MS/MS fragmentation patterns allowing confident assignment of the conjugation sites.

\section{Results and Discussion}

\subsection{Synthesis}

Four $\alpha$-MSH-daunomycin bioconjugates were chosen as model compounds to investigate the most optimal activation technique for the structural characterization of daunomycin-based bioconjugates and to illustrate possible differences in MS/MS fragmentation patterns. The possibility of differentiation between structural isomers was investigated, by incorporating Dau either to the $\mathrm{N}$-terminus or to the side chain of Lys via oxime linkage by using aminooxyacetic acid (Aoa). The two underivatized peptides were used as references with known MS/MS fragmentation behaviors.

The $\alpha$-MSH peptide analogs 1 and 4 were synthetized by solid-phase peptide synthesis using the Fmoc/t $\mathrm{Bu}$ strategy. The Boc-Aoa-OH was coupled to the $N$-terminus (conjugates 2 , and 5 ) or to the $\varepsilon$-amino group of ${ }^{8}$ Lys and ${ }^{11}$ Lys, respectively (conjugates 3 , and 6). Dau was conjugated to the purified aminooxy moiety containing peptides by oxime bond formation in solution ( $0.2 \mathrm{M}$ ammonium acetate buffer, $\mathrm{pH}$ 5.2) [23]. All bioconjugates and their reference peptides were purified by RP-HPLC. The structures of the peptides and bioconjugates and their analytical properties are summarized in Scheme 1 and Table 1. A representative scheme for the synthesis of peptide $\mathbf{1}$ and conjugates $\mathbf{2}$ and $\mathbf{3}$ is shown in the Supporting Information (Scheme S1). Compounds 4-6 have been prepared in the same way.
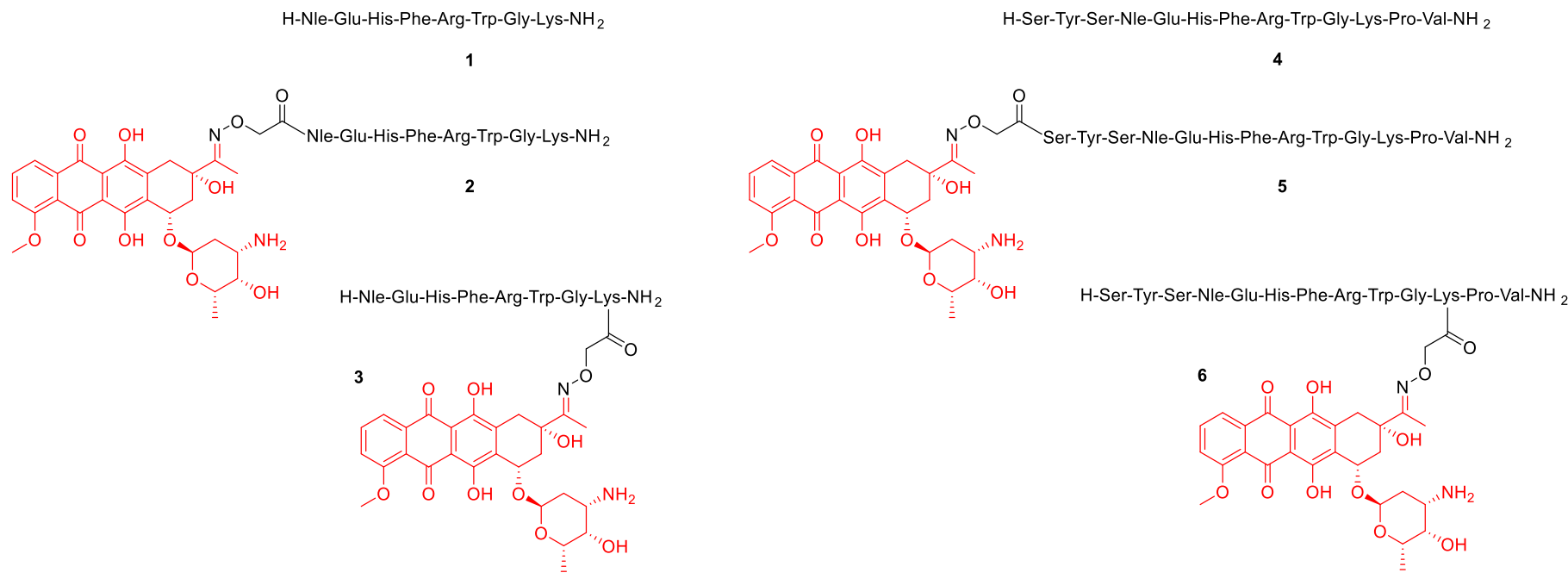

Scheme 1. Molecular structure of the $\alpha$-MSH peptides and bioconjugates.

Table 1. Structural and analytical properties of the $\alpha-\mathrm{MSH}$ analogs and bioconjugates.

\begin{tabular}{|c|c|c|c|c|c|}
\hline & Compound & $m / z$ Calc. for $[\mathrm{M}+2 \mathrm{H}]^{2+}$ & $m / z$ Meas. ${ }^{1}$ for $[\mathrm{M}+2 \mathrm{H}]^{2+}$ & Deviation (ppm) & $\mathbf{R}_{\mathrm{t}}(\min )^{2}$ \\
\hline 1 & H-NleEHFRWGK-NH 2 & 536.2960 & 536.2954 & 1.1 & 6.0 \\
\hline 2 & Dau = Aoa-NleEHFRWGK-NH 2 & 827.3884 & 827.3876 & 1.0 & 8.4 \\
\hline 3 & H-NleEHFRWGK(Dau = Aoa $)-\mathrm{NH}_{2}$ & 827.3884 & 827.3875 & 1.1 & 8.1 \\
\hline 4 & H-SYSNleEHFRWGKPV-NH ${ }_{2}$ & 802.9202 & 802.9192 & 1.2 & 7.2 \\
\hline 5 & Dau = Aoa-SYSNleEHFRWGKPV-NH ${ }_{2}$ & 1094.0127 & 1094.0114 & 1.2 & 8.6 \\
\hline 6 & H-SYSNleEHFRWGK(Dau = Aoa)PV-NH 2 & 1094.0127 & 1094.0115 & 1.1 & 8.6 \\
\hline
\end{tabular}

${ }^{1}$ ESI-MS data measured on a Thermo Scientific Q Exactive Focus mass spectrometer. ${ }^{2}$ Analytical UHPLC was performed using a Waters Acquity UPLC BEH C18 $1.7 \mu \mathrm{m}$ column $(2.1 \times 50 \mathrm{~mm})$, at $40{ }^{\circ} \mathrm{C}$; eluent A: water $+0.1 \%$ formic acid, eluent B: $80 \%$ acetonitrile $+0.1 \%$ formic acid. The following gradient was used: $0 \min 2 \%$ B, 1 min $2 \%$ B, $17 \min 100 \%$ B, $17.5 \min 100 \%$ B, 18 min $2 \%$ B, 21 min $2 \%$ B. The flow rate was $300 \mu \mathrm{L} \mathrm{min}^{-1}$. Dau stands for daunomycin, Aoa stands for aminooxyacetic acid, Nle stands for norleucine. 


\subsection{HCD Experiments}

The HCD MS/MS spectra of the unmodified doubly charged peptides 1 and 4 exhibited significant peptide backbone fragmentation producing singly and doubly protonated $b$ and $y$ type fragments accompanied with neutral losses of water and ammonia. As expected, complete $b$ and $y$ ion series can be detected in the HCD spectrum of the 8-mer peptide 1 when the normalized collision energy was set between $20 \%$ and $40 \%$ (Figure 1A).
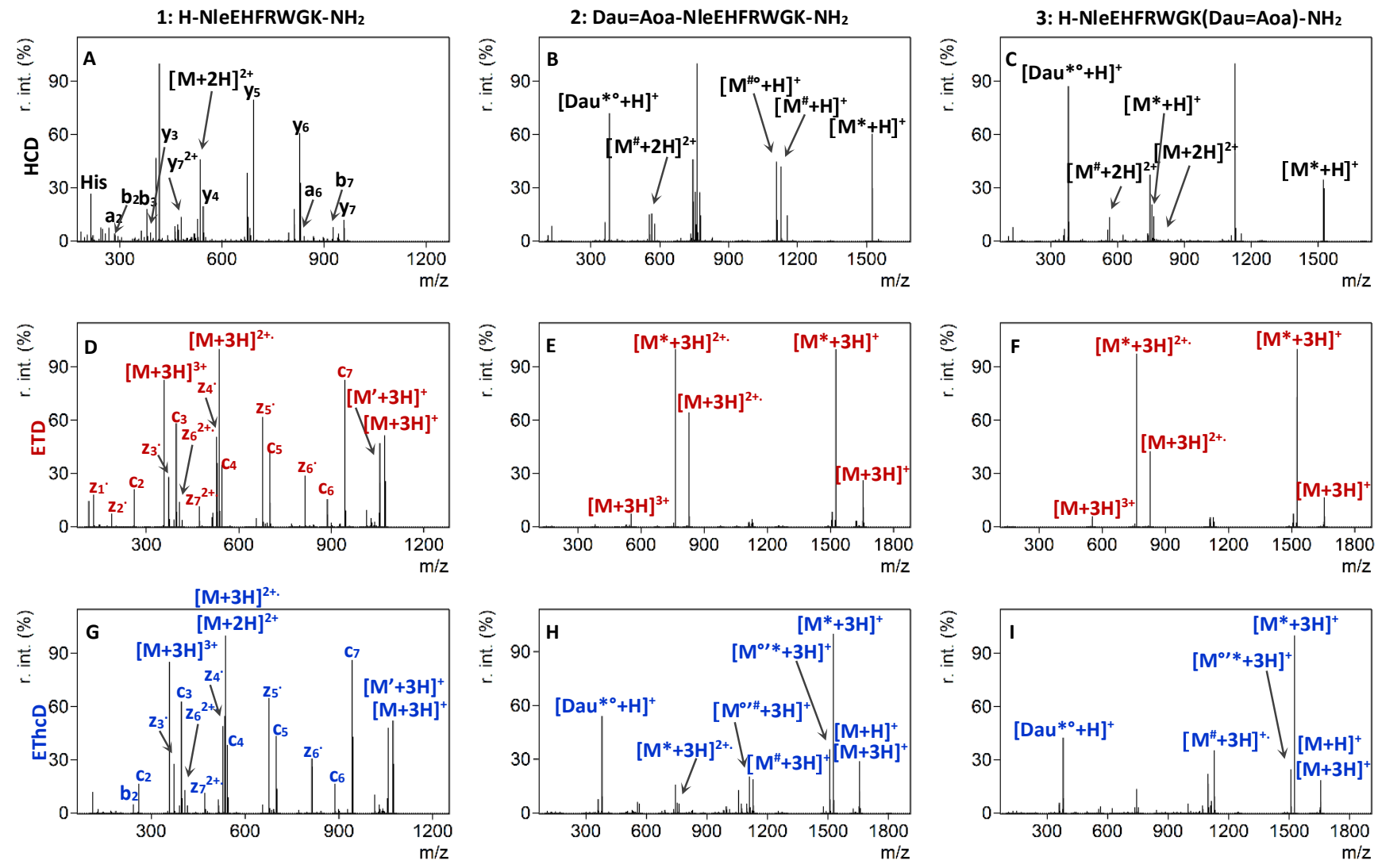

Figure 1. HCD MS/MS spectra of the doubly protonated peptide 1 (A) at $30 \%$ NCE and conjugates 2 (B), and 3 (C) at $20 \%$ NCE. ETD MS/MS spectra of the triply protonated 1 (D), 2 (E), and 3 (F). EThcD MS/MS spectra of the triply protonated 1 (G) at 10\% NCE, and 2 (H) and 3 (I) at 40\% NCE. Neutral losses are depicted as follows: ${ }^{*}=$ sugar, ${ }^{\prime}=\mathrm{NH}_{3},{ }^{\circ}=\mathrm{H}_{2} \mathrm{O}$, \# = Dau + sugar.

The same behavior is observed in the case of the 13-mer peptide 4 between $30 \%$ and $40 \%$ (Figure S1A). In contrast, in the HCD MS/MS spectrum of the doubly charged daunomycin containing conjugates $\mathbf{2}$ and $\mathbf{3}$, the most intense ions correspond to the fragmentation of the anthracycline drug [16], while purely peptide-related fragments could not be detected at low NCE values, up to $20 \%$ (Figure 1B,C). The predominant fragmentation pathway for all daunomycin-peptide conjugates was the loss of the amino sugar of the daunomycin. After cleavage of the $\mathrm{O}$-glycosidic bond between the aglycone part and the daunosamine sugar, initiated by the protonation of the oxygen, the charge can remain either on the sugar portion or on the aglycone moiety, which can subsequently lose a water molecule (Scheme 2). Protonated sugar-lost conjugates are marked with $\left[\mathrm{M}^{*}+\mathrm{H}\right]^{+}$, whereas the subsequent water loss is depicted as $\left[\mathrm{M}^{* \circ}+\mathrm{H}\right]^{+}$. These results correlate with our previously published data, where only the protonated sugar and the protonated, but charge-reduced sugar-lost conjugate could be detected in the HCD MS/MS spectrum of a doubly protonated $\mathrm{Dau}=\mathrm{Aoa}-\mathrm{SKAAKN}-\mathrm{OH}$ conjugate at $10 \mathrm{eV}$ collision energy using a Thermo Scientific $Q$ Exactive Focus mass spectrometer [15].

The N-O bond of the oxime moiety is also prone to fragmentation leading to the loss of daunomycin drug from the conjugate. Our proposed mechanism for the cleavage of 
the $\mathrm{N}-\mathrm{O}$ bond is the acyclic $\beta$-hydrogen rearrangement [24]. Scheme 2 shows the possible route leading to the formation of the imine group containing protonated unsaturated aglycone $\left(\left[\mathrm{Dau}^{* *}+\mathrm{H}\right]\right)$, which can be detected with $m / z 380.1129$, together with protonated oxoacetylated peptide ions marked as $\left[\mathrm{M}^{\#}+\mathrm{H}\right]^{+}$(see also Figure $1 \mathrm{~B}, \mathrm{C}$ ). The exact same fragmentation pattern characterizes the low collision energy HCD MS/MS spectra of conjugates 5 and $\mathbf{6}$ (Figure S1B,C).

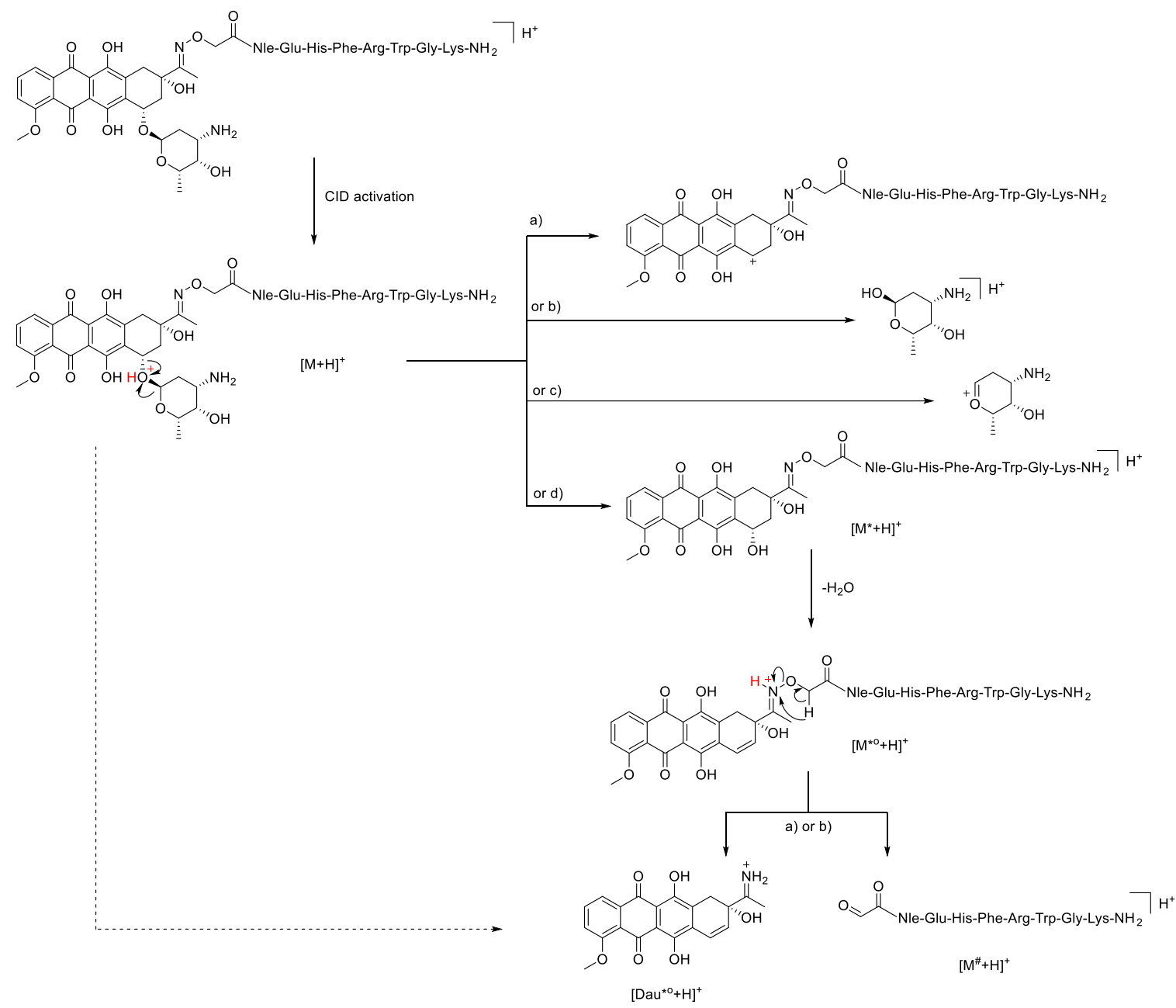

Scheme 2. Cleavage mechanism of the glycosidic bond according to the literature [25], and the fragmentation scheme proposed herein for the loss of Dau moiety by the breakage of the oxime bond. Corresponding neutral fragments formed upon the cleavages of the glycosidic or oxime bonds are present but are not depicted for the ease of readability. Neutral losses are marked as follows: ${ }^{*}=$ sugar, ${ }^{\circ}=\mathrm{H}_{2} \mathrm{O}, \#=$ Dau + sugar.

It was observed, that besides the cleavage of the sugar of the daunomycin moiety, the fragmentation of the peptide backbone also occurred when a higher HCD energy was used. Increasing the collision energy to $25-35 \%$ NCE led to the appearance of a $y_{4}, y_{5}, y_{6}$ and $y_{7}$ ions in the tandem mass spectrum of the doubly charged conjugate 2 , while $b_{3}, b_{5}, b_{6}$ and $b_{7}$ ions could be detected in the case of conjugate 3 (Figure S2). Likewise, uncomplete $y$ and $b$ ion series could be detected in conjugates 5 and $\mathbf{6}$, containing the longer homing peptide. Thus, no direct correlation could be established between the length of the peptide chain and its effect on the fragmentation. Remarkably, the intensity and abundance of peptide sequence related fragments remained inferior to the cleavage of the daunosamine moiety.

The observation that higher charge states allow for easy fragmentation has initiated the investigation of the fragmentation behaviors of triply protonated conjugates. Although doubly protonated unmodified peptides are mainly in the focus of HCD fragmentation 
techniques, conjugation of the peptides with daunomycin increased both the molecular weight and the basicity of the conjugates. Therefore, we hypothesized that selection of higher charge states may be required for the effective fragmentation of conjugates containing daunomycin modification. Hence, we used higher collision energies for the MS/MS fragmentation of triply protonated conjugates $\mathbf{2 , 3 , 5}$ and $\mathbf{6}$. A comparative example can be seen in Figure 2. The HCD MS/MS spectrum of the doubly protonated conjugate 5 at $20 \%$ contained only the doubly protonated sugar lost molecule (Figure 2A), while, on the other hand, the tandem mass spectrum of the triply protonated conjugate 5 at $30 \%$ NCE showed a complete $y$ series, while $b$ and $a$ ions were not observed (Figure 2D). These results demonstrated that an appropriate selection of the precursor charge state and HCD energy can ultimately result in efficient peptide backbone fragmentation of the conjugates. Apparently, higher energies and higher charge states were required to "mobilize" the protons to facilitate charge-directed backbone cleavages [26]. These protons were sequestered not only at the basic side chain containing amino acids, such as Arg or Lys, but most probably also at daunosamine sugar part.
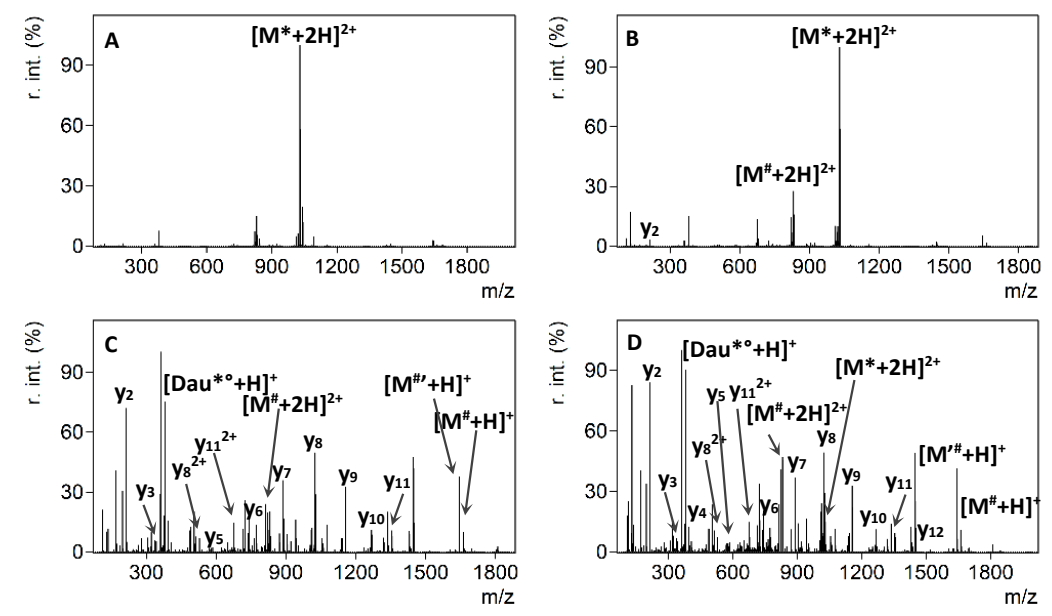

Figure 2. HCD MS /MS spectra of the doubly and triply protonated conjugate 5 at $20 \%$ NCE (A,B, respectively) and at $30 \% \mathrm{NCE}\left(\mathbf{C}, \mathbf{D}\right.$, respectively). Neutral losses are depicted as follows: ${ }^{*}=$ sugar, $'=\mathrm{NH}_{3},{ }^{\circ}=\mathrm{H}_{2} \mathrm{O}$, \# = Dau + sugar.

Based on the results of the above experiments we concluded that efficient HCD fragmentation depends on the selected charge state and HCD energy. Doubly protonated control peptides fragment more easily at a wide NCE\% range. However, higher energy onset and the selection of higher charge state precursors are required for the fragmentation of the daunomycin conjugates and for the enhanced sequence coverage (Table 2).

Table 2. Fragmentation efficiency of the $\alpha-\mathrm{MSH}$ analogs and bioconjugates by HCD, ETD and EThcD fragmentation techniques.

\begin{tabular}{|c|c|c|c|c|c|}
\hline Compound & $z$ & $\begin{array}{c}\text { Low E HCD (NCE } \\
\leq \mathbf{2 0} \%)\end{array}$ & $\begin{array}{l}\text { High E HCD } \\
(\mathrm{NCE} \geq 25 \%)\end{array}$ & ETD & EThcD \\
\hline $1 ;(4)$ & $\begin{array}{l}2 \\
3\end{array}$ & $\begin{array}{c}+;(-) \\
+++;(++)\end{array}$ & $\begin{array}{l}++;(+++) \\
+++;(++)\end{array}$ & $\begin{array}{c}++ \\
+++;(++)\end{array}$ & $\begin{array}{c}++^{\mathrm{a}} \\
+++(++)^{\mathrm{a}}\end{array}$ \\
\hline $\begin{array}{c}2 ;(5) \\
\text { Dau at } N \text {-terminus }\end{array}$ & $\begin{array}{l}2 \\
3\end{array}$ & $\begin{array}{c}- \\
+;(-)\end{array}$ & $\begin{array}{l}++ \\
++\end{array}$ & - & $\begin{array}{c}+;(++)^{\mathrm{b}} \\
-;(+)^{\mathrm{b}}\end{array}$ \\
\hline $\begin{array}{c}3 ;(6) \\
\text { Dau at Lys }\end{array}$ & $\begin{array}{l}2 \\
3\end{array}$ & $\begin{array}{l}- \\
-\end{array}$ & $\begin{array}{l}+;(++) \\
+;(++)\end{array}$ & $\begin{array}{l}- \\
-\end{array}$ & $\begin{array}{l}-\mathrm{c} \\
-\mathrm{d}\end{array}$ \\
\hline
\end{tabular}

Symbols: $-:$ no peptide sequence related fragments; + : the sequence coverage is $10-30 \%$, where the relative intensity of the fragments is $\geq 5 \%$; + : the sequence coverage is $31-60 \%$, where the relative intensity of the fragments is $\geq 5 \%$; + + + the sequence coverage is $>61 \%$, where the relative intensity of the fragments is $\geq 5 \%$; $\mathrm{NCE}=10 \%,{ }^{\mathrm{b}} \mathrm{NCE}=40 \%,{ }^{\mathrm{c}} \mathrm{NCE}=30 \%,{ }^{\mathrm{d}} \mathrm{NCE}=35 \%$. Values for the compounds 4 , 5 and $\mathbf{6}$ are in brackets. 


\subsection{ETD and EThcD Experiments}

Electron-transfer dissociation is the method of choice for the identification of long and highly charged peptides. ETD outperforms CID or HCD for charge states higher than 2 and induces more backbone cleavages, thus increasing the peptide sequence coverage [27]. ETD is better than other similar methods, because it preserves post-translational modifications (PTMs), which are often labile after CID, thereby making available all relevant sequence information [28]. Therefore, triply charged ions were selected for ETD fragmentation in our experiments. In the case of peptides 1 and 4, ETD MS/MS resulted in a virtually complete or almost complete sequence coverage. For peptide $\mathbf{1}$, all seven $\mathrm{N}-\mathrm{C}_{\alpha}$ bonds were cleaved generating a complete series of $c$ and $z^{\bullet}$-type fragment ions (Figure 1D). Surprisingly, conjugation of daunomycin to the $\alpha-\mathrm{MSH}$ tumor homing peptides drastically inhibited the $\mathrm{N}-\mathrm{C}_{\alpha}$ backbone cleavage following electron transfer by triply charged conjugate ions. The ETD MS/MS spectra of conjugates $\mathbf{2}$ and $\mathbf{3}$ were poor, containing only four intense fragment ions, namely the $[\mathrm{M}+3 \mathrm{H}]^{3+}$ precursor and the $[\mathrm{M}+3 \mathrm{H}]^{2+\bullet}$ charge-reduced species, together with sugar-lost conjugates $\left[\mathrm{M}^{*}+3 \mathrm{H}\right]^{+}$and $\left[\mathrm{M}^{*}+3 \mathrm{H}\right]^{2+\bullet}($ Figure $1 \mathrm{E}, \mathrm{F})$. The backbone fragmentation was incomplete regardless of the length of the targeting peptide or the position of the drug in the bioconjugates (Figure S1E,F).

The presence of specific functional moieties within a peptide sequence can limit the fragmentation of the peptide backbone in ETD or electron-capture dissociation (ECD). This phenomenon can be explained by the "electron predator" effect. This model, first described by Sohn et al. [29], proposes the presence of a functional group (i.e., 3-nitrobenzyl [29] or 3-nitrotyrozyl $[30,31]$ groups) with high electron affinity (EA), that captures electrons and forms a stable radical intermediate inhibiting peptide backbone fragmentation in ETD or ECD. These disadvantageous features limit the application of these two techniques for peptide identification containing such modifications. In general, substituents with $\mathrm{EA}>1.00 \mathrm{eV}$ are mentioned as "electron predator" that completely prevent $\mathrm{N}-\mathrm{C}_{\alpha}$ backbone cleavage [29]. Anthracyclines contain the 9,10-anthraquinone nucleus which has high EA $(1.59 \mathrm{eV})$ [32], as well as undergo gas-phase reactions indicative of their high EAs [33]. Furthermore, anthracycline antibiotics are involved in single electron transport mechanisms in microsomes [34]. Considering that anthracycline drugs, such as daunomycin, fulfill the beforementioned high EA criteria and produce an incomplete backbone fragmentation, as was observed herein in the case of all four conjugates, this class of drugs can be considered as new members of the "electron predator" family.

Compared with HCD and ETD, the electron transfer and higher energy collisional dissociation $(\mathrm{ETh} C \mathrm{D})$ technique provides a considerable increase in peptide backbone fragmentation of doubly charged peptides and enables a confident structure identification [21], including the localization of different PTMs [35-37]. Therefore, we anticipated that this method can be successfully applied for the analysis of daunomycin conjugates. Although the EThcD MS/MS spectrum of the triply charged peptide ions at $40 \%$ NCE produced numerous $b, c$, and $z^{\bullet}$ fragments, as well as charge-reduced precursor ions and several neutral losses (Figure 1G), the spectra of the triply charged conjugates $\mathbf{2}$ and 3, measured with $40 \%$ NCE, were dominated by charge-reduced precursors, and sugar- and Dau-lost ions (Figure 1H,I). Similar to the results of ETD measurement, no peptide backbone fragmentation could be observed in the case of the daunomycin-peptide conjugates. Likewise, the transfer of electrons can be captured by the daunomycin conjugated either to the $\mathrm{N}$ terminus or the Lys side chain of the peptides and the subsequent collisional activation halts the cleavage of the peptide chain. The MS/MS spectrum of peptide 4 also shows abundant fragmentation, whereas the spectra of conjugates $\mathbf{5}$ and $\mathbf{6}$ mainly contains losses of sugar and the Dau moiety, which was accompanied by ammonia loss of charge-reduced precursors (Figure $\mathrm{S} 1 \mathrm{H}, \mathrm{I})$.

Based on the results of these experiments we concluded that none of the electron transfer-based techniques gives a reliable analytical characterization of the daunomycin conjugates. The ETD and EThcD MS/MS spectra of the selected conjugates did not contain beneficial information for interpreting the peptide sequence nor the position of the dauno- 
mycin. The fragmentation efficiency of $\alpha$-MSH analogs and Dau-conjugates by HCD, ETD and EThcD activation methods is summarized in Table 2.

\subsection{MALDI-TOF/TOF Experiments}

Matrix-assisted laser desorption/ionization (MALDI) based tandem mass spectrometry has also been proved as a powerful tool in structural characterization of peptide and protein samples [22,38]. In MALDI-TOF/TOF, peptide fragmentation can be obtained by laser-induced dissociation (LID) or high-energy collision-induced dissociation (CID), known as real MS/MS techniques and in-source decay (ISD) as a pseudo-MS/MS technique [39]. Typically, in MS/MS mode singly charged precursor ions are selected and fragmented. Moreover, singly charged fragment ions are analyzed in this mode. These result in a simplified product ion spectrum and enable rapid interpretation as well as accurate sequencing. By comparison, MALDI-ISD involves a prompt fragmentation occurring in the MALDI ion source, and generates the cleavage of the peptide backbone bonds, thus, leading to sequence specific information [40].

First, peptides and bioconjugates were fragmented by ISD (Figure 3A-C, Figure S3A-C respectively). All spectra contained abundant $[\mathrm{M}+\mathrm{H}]^{+}$ions and a few fragment ion peaks, because the efficiency of producing fragment ions via the MALDI-ISD mode is relatively low for short peptides [41]. The MALDI-ISD spectra of peptides $\mathbf{1}$ and $\mathbf{4}$ contains a very small number of fragments with low abundance. Similarly to HCD, in the case of all conjugates the favored fragmentation pathways include the neutral loss of the sugar moiety from the daunomycin, as well as the loss of the daunomycin molecule (Scheme 2), accompanied by additional losses of ammonia and water from these fragments (Figure 3B,C, and Figure S3B,C). The ISD dissociation of daunomycin conjugates also yielded very few peptide-related fragments and a large portion of unassigned peaks in the lower mass region (300-500 m/z). In our experiments, the DHB matrix was used, which favors the production of $a-, b-$, and $y$-ions via the thermal fragmentation pathway due to its low proton affinity [40].

Besides different neutral losses, the LID fragmentation of peptides 1 and 4 yielded a mixture of incomplete $a, b$ and $y$ series, and the sequence coverage for the 13-mer peptide 4 being greater than for the 8-mer analog 1 (Figure 3D, and Figure S3D). The MALDI-LID-MS/MS spectra which were acquired from the singly protonated precursors of conjugates $\mathbf{2}$ and $\mathbf{3}$ are shown in Figure 3E,F, respectively, whereas those of conjugates $\mathbf{5}$ and $\mathbf{6}$ are shown in Figure S3E,F, respectively. Although the sugar-lost conjugate was the most dominant fragment ion in the MS/MS spectra of all daunomycin conjugates, fragmentation of the peptide backbone amide bonds was also detectable with various intensities. The His immonium ion and the $y_{6} \#$ fragment were recorded for conjugate 2 , where Dau is conjugated to the $N$-terminus, while $b_{3}, b_{5}, a_{6}$, and $y_{4}{ }^{*}$ fragment ions were observed for conjugate 3 , in which Dau is attached to the Lys side chain (neutral losses: \# = Dau + sugar, ${ }^{*}=$ sugar $)$. Higher mass $a$-type fragment ions $\left(a_{8}, a_{12}\right.$ and $a_{9}, a_{12}$, respectively) gained intensity when the conjugates contained the longer 13-mer targeting peptide (i.e., conjugates 5 , and 6 ).

These results revealed a clear dependency of the peptide backbone fragmentation on the position of the daunomycin in the conjugates. Fragment ions, which were present when Dau was conjugated on the $N$-terminus were, however, not detectable when the drug was attached to the Lys, and vice versa. In addition, the length of the peptide chain also affected the MALDI-LID fragmentation behavior of daunomycin conjugates. However, the abundance and intensity of the targeting peptide-related fragments was still low compared to the intensity of fragment ions corresponding to the decomposition of the anthracycline drug. Therefore, the present data were insufficient to determine the conjugations sites or identify the sequence. 
1: H-NleEHFRWGK-NH2
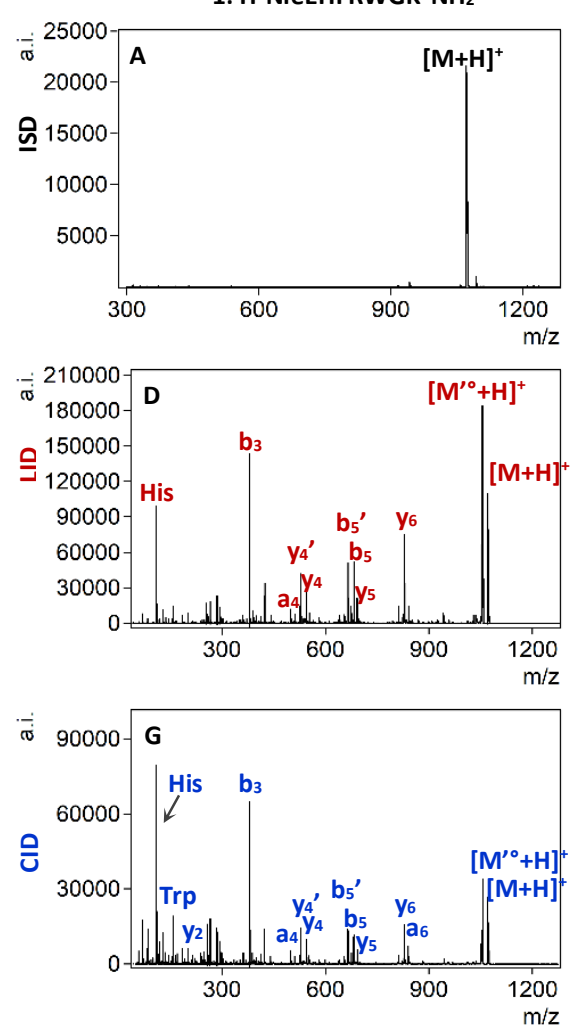

2: Dau=Aoa-NleEHFRWGK- $\mathrm{NH}_{2}$
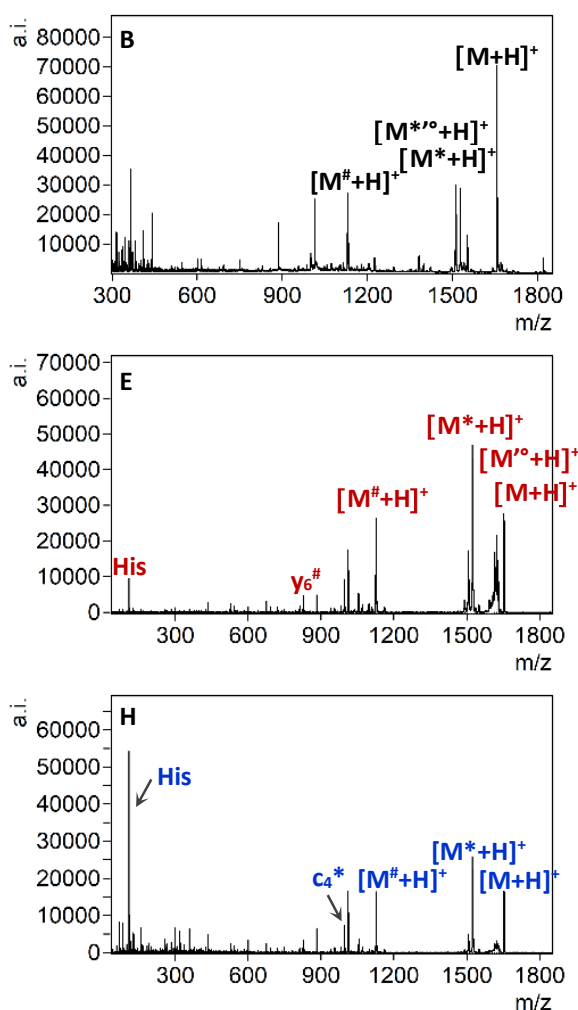

3: H-NleEHFRWGK(Dau=Aoa)- $\mathrm{NH}_{2}$
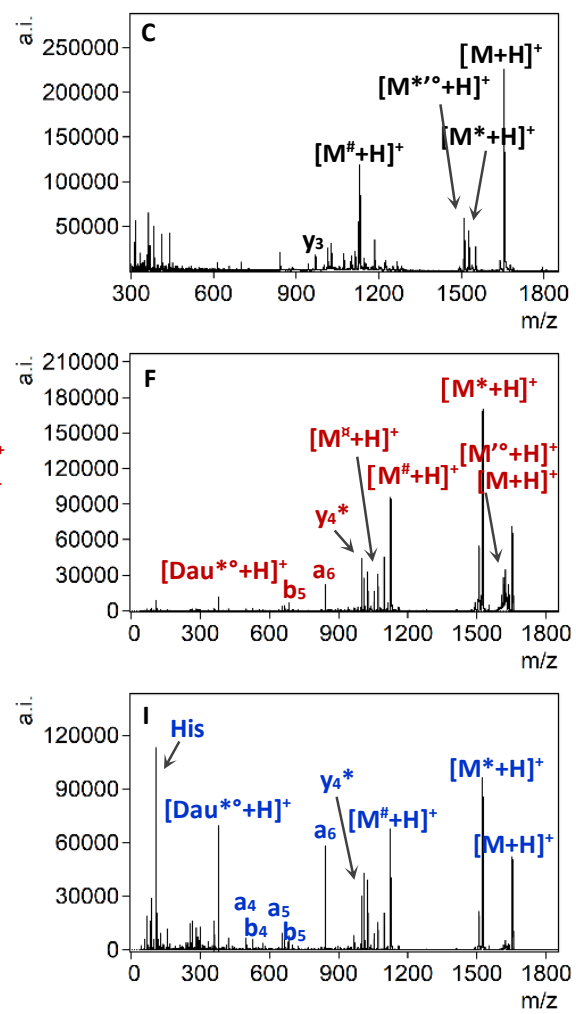

Figure 3. MALDI MS/MS spectra of the singly protonated compounds 1, 2, and 3. (A-C) MALDI-ISD spectra, (D-F) MALDI-TOF/TOF LID spectra, (G-I) MALDI-TOF/TOF CID spectra. Neutral losses are depicted as follows: * $=$ sugar, $'=\mathrm{NH}_{3},^{\circ}=\mathrm{H}_{2} \mathrm{O}, \#=$ Dau + sugar.

The CID spectrum of peptide $\mathbf{1}$ using $\mathrm{N}_{2}$ as collision gas contained more fragment ions compared to the LID spectrum because of their different fragmentation pattern (Figure 3G). We also observed that the fragment ions' signal intensity and abundance was clearly shifted to the lower third of the mass region according to the result of CID activation for peptide 4 (Figure S3G). This effect is presumably due to multiple collision and fragmentation events resulting in fewer mass fragments. The same behavior was reported by Macht et al. in a comparative study of the LID and CID fragmentation processes for ACTH (1-17), a structural analog of peptide 4 , and other peptides [42].

Remarkably, the MALDI-CID activation of the daunomycin-conjugate precursor ions produced a more informative product ion spectrum, some characteristic peptide-sequencerelated fragments had comparable intensity to those of sugar and Dau loss fragments (Figure 3H,I, Figure S3H,I. Most notably, the relative intensity of specific $a$-type ions showed a significant increase compared to the respective LID spectra. By comparing the MALDI-CID spectra of conjugates 2 with 3 and 5 with 6 , it can be observed that the fragmentation pattern was influenced by the position of the daunomycin. In fact, if Dau was conjugated to the $\mathrm{N}$-terminus (conjugates 2, and 5), several unassigned signals as well as middle-sized $y$ and $b$-type fragment ions are observed in the spectrum. These low intensity fragments are most probably formed due to the MALDI laser-induced excitation of the Dau at the $\mathrm{N}$-terminus, which directed the fragmentation to the middle of the peptide chain. A characteristic $a$-fragment ion $\left(a_{8}\right)$ was only present when the longer homing peptide was used (Figure $\mathrm{S} 3 \mathrm{H}$ ), indicating that the effect of this phenomenon may be dependent on the length of the peptide chain. In contrast, besides small fragments, a very intense $a$-type ion was detectable in the MALDI-CID spectrum of conjugates 3 and $\mathbf{6}$, in which Dau was conjugated to the $\varepsilon$-amino group of the Lys. The $a_{6}$ and $a_{9}$ ions (for conjugates $\mathbf{3}$ and $\mathbf{6}$, respectively) were both produced by the breakage of the $\alpha$-carbon to carbonyl-carbon bond $(\mathrm{CH}-\mathrm{CO})$ between the Trp and Gly. Preferential cleavage was also found at $\mathrm{N}$-terminal to 
Gly by Khatun et al. resulting in $y$ fragments [43]. The fragmentation efficiency of $\alpha$-MSH analogs and bioconjugates by MALDI MS/MS is summarized in Table 3.

Table 3. Fragmentation efficiency of singly protonated $\alpha$-MSH analogs and bioconjugates by MALDI MS/MS.

\begin{tabular}{cccc}
\hline Compound & ISD & LID & CID \\
\hline $\mathbf{1} ;(4)$ & - & $++;(+++)$ & $+++;(++)$ \\
\hline $2 ;(5)$ & - & + & + \\
Dau at $N$-terminus & - & $++;(+)$ & $++;(+)$ \\
\hline $3 ;(6)$ & & & \\
Dau at Lys & & & \\
\hline
\end{tabular}

Symbols: -: no peptide sequence related fragments; + : the sequence coverage is $10-30 \%$, where the relative intensity of the fragments is $\geq 5 \%$; + +: the sequence coverage is $31-60 \%$, where the relative intensity of the fragments is $\geq 5 \%$; + + : the sequence coverage is $\geq 61 \%$, where the relative intensity of the fragments is $\geq 5 \%$. Values for the compounds 4 , and 6 are in brackets.

To verify whether the characteristic fragment ions were indeed generated through the high-energy CID process, we selected structurally more complex peptide conjugates and subjected them to MALDI MS/MS analysis. The 19-mer Angiopep-2 peptide (7, HTFFYGGSRGKRNNFKTEEY-OH, Scheme 3), which is a specific ligand of the low density lipoprotein 1 (LRP-1) [44], contains three potential sites for conjugation. Daunomycin can be conjugated either to the $N$-terminus of the peptide or to one of the lysine side chains in the sequence $\left({ }^{10} \mathrm{Lys}\right.$ or $\left.{ }^{15} \mathrm{Lys}\right)$ resulting in three daunomycin conjugate isomers (8-10, Scheme 3).

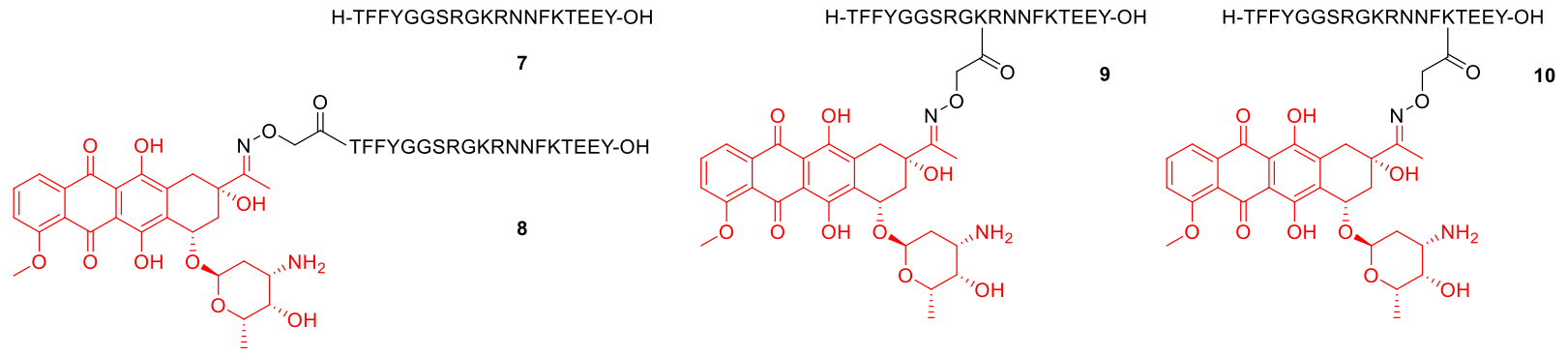

Scheme 3. Molecular structure of the Angiopep-2 (7) and Angiopep-2-daunomycin conjugates 8, 9 and 10.

Figure 4 shows the MALDI-CID spectra of Angiopep-2 (7) and conjugates 8, 9 and 10 acquired using identical conditions as before. In general, neutral loss of the sugar and Dau moiety was detectable for all three conjugates. Furthermore, the fragmentation pathways of the three conjugates significantly differed from each other. The comparison of the MALDI-CID spectra confirmed a different fragmentation behavior for conjugates containing $N$-terminal and Lys modification. In the case of conjugate 8 , which contained Dau at its $\mathrm{N}$-terminus, the peptide backbone fragmentation was limited. Moreover, the $y$-type ions were present with low abundance and intensity. In addition, immonium ions were obtained with slightly higher intensities (Figure 4B). While the iminium ion region of the tandem mass spectrum of conjugates $\mathbf{9}$ and $\mathbf{1 0}$ was similar to that of conjugate $\mathbf{8}$, lower mass ions (i.e., $a_{2}, b_{2}$ and $b_{3}$ ) showed increased intensity and specific fragment ions gained significant abundance in the middle mass region when Dau was conjugated to one of the Lys side chains (Figure 4C and 4D, respectively). Furthermore, a comparison of the tandem mass spectrum of $\mathbf{9}$ with $\mathbf{1 0}$, in which Dau was conjugated to the $\varepsilon$-amino group of the ${ }^{10} \mathrm{Lys}$ or ${ }^{15}$ Lys, revealed a considerable difference in terms of the dominant fragment ions present in each spectrum. The $a$-type fragment ions, containing or in the vicinity of the modified Lys, were the most intense fragments. While the $a_{10}{ }^{\text {a }}$ was the dominant fragment ion in the 
tandem mass spectrum of conjugate $9, a_{14}$ ion became the most abundant fragment in the MALDI-CID spectrum of conjugate $\mathbf{1 0 .}$
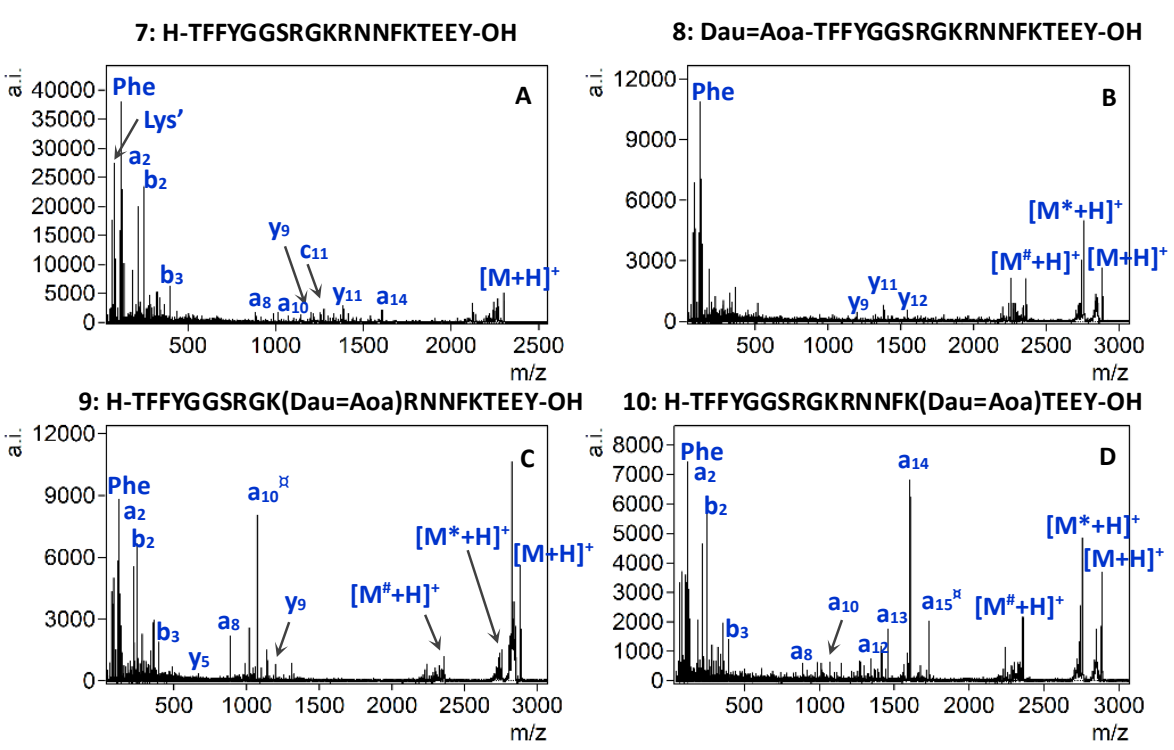

Figure 4. MALDI-CID-MS/MS spectra of the compounds 7 (A), 8 (B), 9 (C), and 10 (D). Neutral losses are depicted as follows: ${ }^{*}=$ sugar, ${ }^{\prime}=\mathrm{NH}_{3},^{\circ}=\mathrm{H}_{2} \mathrm{O}, \#=\mathrm{Dau}+$ sugar, $\mathrm{a}=\mathrm{Dau}+$ sugar + Aoa.

The presence of the highly intense $a_{10}$ or $a_{14}$ fragments, together with the absence of these in the MS/MS spectrum of the respective conjugate isomer pair, ensured unambiguous localization of the conjugation site. This information allows a reliable analytical characterization of large peptide-drug conjugates that contain multiple conjugation sites.

\section{Materials and Methods}

\subsection{Synthesis of the Daunomycin-Peptide Conjugates}

All amino acid derivatives, the Rink-amide MBHA resin, Wang resin, $N, N^{\prime}$-diisopropy lcarbodiimide (DIC), and trifluoroacetic acid (TFA) were purchased from Iris Biotech GmbH (Marktredwitz, Germany). Boc-aminooxyacetic acid (Boc-Aoa-OH), 1-hydroxybenzotriazole hydrate (HOBt), triisopropylsilane (TIS), and hydrazine hydrate were obtained from Sigma Aldrich Kft. (Budapest, Hungary), 1,8-diazabicyclo[5.4.0]undec-7-ene (DBU) was acquired from TCI Europe N.V. (Zwijndrecht, Belgium), and piperidine was purchased from Molar Chemicals Kft (Budapest, Hungary).

The peptides 1 and 4 were manually synthetized using the standard Fmoc $/ \mathrm{Bu}$ strategy on Rink-Amide MBHA resin $\left(0.69 \mathrm{mmol} \mathrm{g}^{-1}\right)$. For the synthesis of Dau containing conjugates 2 and 5, the $N$-terminal Fmoc group was cleaved with $2 \%$ piperidine $+2 \%$ DBU in DMF $(2+2+5+10$ min), while for the synthesis of conjugates 3 and 6 , the Lys side chain protecting group (Dde) was selectively cleaved with $2 \%$ hydrazine hydrate $(6 \times 2 \mathrm{~min})$. Boc-Aoa-OH was coupled either to the $N$-terminus or to the $\varepsilon$-amino group of the Lys using the standard Fmoc/ $t \mathrm{Bu}$ protocol. Peptides were cleaved from the resin with $95 \%$ TFA, $2.5 \%$ water, $2.5 \%$ TIS $(v / v / v \%)$ for $2 \mathrm{~h}$ at room temperature. The crude peptides were lyophilized, purified by RP-HPLC, and the pure Aoa-derivatized fractions were immediately used for the next step. Daunomycin was conjugated to the peptides in solution (0.2 M ammonium acetate buffer, $\mathrm{pH}$ 5.2) [23]. The mixture was stirred for 2 days and the conjugates $2,3,5$, and $\mathbf{6}$ were obtained after RP-HPLC purification.

Peptide 7 was synthetized using the standard Fmoc/tBu strategy on Wang resin $\left(0.45 \mathrm{mmol} \mathrm{g}^{-1}\right)$. For the synthesis of 9 and 10, Fmoc-Lys (Dde)-OH was incorporated in positions 10 and 15, respectively. The following steps were performed as described above. 


\subsection{Instruments}

Prior to HCD, ETD and EThcD measurements, freeze-dried samples were diluted to $10 \mu \mathrm{M}$ final concentration with acetonitrile-water $(1: 1, v / v)$ containing $0.1 v / v \%$ formic acid. Solutions were directly injected into the electrospray source of an Orbitrap Fusion Tribrid instrument (Thermo Scientific, Waltham, MA, USA) at a flow rate of $5 \mu \mathrm{L} \mathrm{min}{ }^{-1}$. Samples were ionized with $3500 \mathrm{~V}$ constant current in positive mode. The flow rate of the sheath gas was approximately $0.6 \mathrm{~L} \mathrm{~min}^{-1}$ and the flow rate of the aux gas was approximately $2.5 \mathrm{~L} \mathrm{~min}^{-1}$. The vaporizer temperature was set to $30^{\circ} \mathrm{C}$ and the temperature of the ion transfer tube was $300{ }^{\circ} \mathrm{C}$. Resolution was set to 120,000 . An isolation width of $2 \mathrm{~m} / \mathrm{z}$ was applied for MS/MS. For ETD and EThcD experiments, the ion activation time was set to $50 \mathrm{~ms}$. Normalized collision energies (NCE) were set between 5 and $45 \%$ for HCD and EThcD.

Prior to MALDI-TOF/TOF measurements, samples were dissolved in acetonitrilewater $(1: 1, v / v)$ containing $0.1 \%$ TFA. 2,5-dihydroxybenzoic acid (DHB, $100 \mathrm{mg} / \mathrm{mL}$, acetonitrile-water $(1: 1, v / v \%)$ with $0.1 \%$ TFA) was used as matrix. The matrix and the sample were mixed in the ratio of 1:1 and $0.25 \mu \mathrm{L}$ was deposited onto the stainless steel 384well sample plate and allowed to air-dry. MALDI-TOF/TOF measurements were carried out with a Bruker Autoflex Speed mass spectrometer (Bruker Daltonics, Bremen, Germany) operating in the reflectron positive ion mode. For ISD measurements $19 \mathrm{kV}$ (ion source voltage 1), $16.7 \mathrm{kV}$ (ion source voltage 2), $21 \mathrm{kV}$ (reflector voltage 1) and $9.65 \mathrm{kV}$ (reflector voltage 2) voltages were used. For LIFT measurements $6 \mathrm{kV}$ (ion source voltage 1), $5.25 \mathrm{kV}$ (ion source voltage 2), $27 \mathrm{kV}$ (reflector voltage 1 ) and $11.65 \mathrm{kV}$ (reflector voltage 2) voltages were applied. The solid phase laser $(355 \mathrm{~nm})$ was operated at $500 \mathrm{~Hz}$ and 2000 shots were summed. The spectra were externally calibrated using adequate standard peptides (Bruker Daltonics, Bremen, Germany). The CID experiments were performed applying nitrogen as collision gas at a pressure level of $6 \times 10^{-6} \mathrm{mbar}$ in the source region (MALDI-CID). The mass resolution of the MALDI-CID measurements was 1400 at $\mathrm{m} / z 400$ and 3300 at $\mathrm{m} / \mathrm{z}$ 2100, determined by the spectra of sample 7 .

All spectra were analyzed with Xcalibur (version 3.1.66.10, Thermo Scientific, Waltham, MA, USA) and/or Mmass [45].

\section{Conclusions}

Sequencing and identifying the structures of daunomycin-peptide conjugates are considerably challenging owing to their complex structures and the prominent fragmentation of this anthracycline drug. In a previous study, we demonstrated that in-source and HCD fragmentation of daunomycin conjugates leads to the loss of the sugar moiety from the daunomycin, resulting in complex spectra, whereas the peaks of intact protonated conjugates are of low intensity.

In the present work, we aimed to identify an adequate MS/MS method that provided high sequence coverage for a reliable structural identification of daunomycin conjugates. We found that daunomycin-related fragmentation is still the major fragmentation pathway using the most common fragmentation techniques, namely, HCD, ETD and EThcD. Conjugation of the peptides with daunomycin increased both the molecular weight and the gas-phase basicity of the conjugates. Such chemical modification greatly influenced the fragmentation efficiency of the bioconjugates, higher energies and higher charge states were required to "mobilize" the protons and facilitate charge-directed backbone cleavages than for the unmodified peptides. Based on these results, an appropriate selection of the precursor charge state and HCD energy can provide a complete sequence coverage and facilitate the conjugation site assignment.

We have also shown that peptide backbone fragmentation was inhibited in these conjugates using ETD or EThcD methods, most possibly due to the "electron predator" effect of the daunomycin.

MALDI-TOF/TOF analysis of daunomycin bioconjugates yielded structural information about the targeting peptide and allowed discrimination between different drug 
conjugation sites even in the case of large and complex molecules. When used along with collisional activation, the MALDI-MS/MS spectra of the conjugates were dominated by fragments related to characteristic peptide sequences aside from the facile sugar and daunomycin lost fragments. The presence of intense a-ions, which corresponded to the peptide backbone cleavage at or within the vicinity of Lys residues that contained the modifications, improved the localization of side chain conjugations. However, MALDI-TOF/TOF provided an incomplete sequence coverage.

We envision that MALDI-CID-MS/MS will be the method of choice for structure identification and comprehensive characterization of peptide-drug conjugates containing anthraquinone, quinoline or other polyheterocyclic analogs as payloads.

Supplementary Materials: The following are available online at https:/ / www.mdpi.com/1422-0 067/22/4/1648/s1, Scheme S1: Synthesis of the peptide 1 and Daunomycin- $\alpha$-MSH conjugates 2 and 3. Figure S1: HCD MS/MS spectra of doubly protonated 4 (A) at 30\% NCE, 5 (B) and 6 (C) at 20\% NCE. ETD MS/MS spectra of triply protonated 4 (D), 5 (E) and 6 (F). EThcD MS/MS spectra of triply protonated $4(\mathrm{G})$ at 10\% NCE, $5(\mathrm{H})$ at $40 \% \mathrm{NCE}$ and $6(\mathrm{I})$ at 30\% NCE, Figure S2: HCD MS/MS spectra of triply protonated 5 (A) and 6 (B) at 20\% NCE, Figure S3: MALDI MS/MS spectra of the singly protonated compounds 4, 5, and 6. A, B, C: MALDI-ISD spectra, D, E, F: MALDI-TOF/TOF LID spectra, G, H, I: MALDI-TOF/TOF CID spectra. Table S1: Structural and analytical properties of the Angiopep-2 and Angiopep-2-bioconjugates. MS spectra of the compounds 1-10.

Author Contributions: Conceptualization: A.B. and G.S.; synthesis: L.P., I.S., M.A.-M. in consultation with G.M.; data analysis: A.B., L.P., A.S.; HCD, ETD, EThcD measurements: G.K. and É.C.; MALDI measurements: A.B., M.A.-M., T.N., S.K.; the manuscript and the Supporting Information were written by A.B. All authors have read and agreed to the published version of the manuscript.

Funding: The research was supported by the National Research, Development and Innovation Office (NVKP_16-1-2016-0036) and the Lendület (Momentum) Program of the Hungarian Academy of Sciences (HAS, MTA). The research within Project No. VEKOP-2.3.3-15-2017-00020, GINOP-2.3.3-152016-00020 and GINOP 2.3.3-15-2016-00021 were supported by the European Union and the State of Hungary, cofinanced by the European Regional Development Fund. Project No. 2018-1.2.1-NKP-201800005 has been implemented with the support provided from the National Research, Development and Innovation Fund of Hungary, financed under the 2018-1.2.1-NKP funding scheme.

Institutional Review Board Statement: Not applicable.

Informed Consent Statement: Not applicable.

Data Availability Statement: Data is contained within the article or Supplementary Material.

Conflicts of Interest: The authors declare no conflict of interest.

\section{References}

1. Vrettos, E.I.; Mező, G.; Tzakos, A.G. On the design principles of peptide-drug conjugates for targeted drug delivery to the malignant tumor site. Beilstein J. Org. Chem. 2018, 14, 930-954. [CrossRef] [PubMed]

2. Le Joncour, V.; Laakkonen, P. Seek \& Destroy, use of targeting peptides for cancer detection and drug delivery. Bioorg. Med. Chem. 2018, 26, 2797-2806. [PubMed]

3. Chatzisideri, T.; Leonidis, G.; Sarli, V. Cancer-targeted delivery systems based on peptides. Future Med. Chem. 2018, 10, 2201-2226. [CrossRef] [PubMed]

4. Slominski, A.; Wortsman, J.; Luger, T.; Paus, R.; Solomon, S. Corticotropin releasing hormone and proopiomelanocortin involvement in the cutaneous response to stress. Physiol. Rev. 2000, 80, 979-1020. [CrossRef] [PubMed]

5. Morandini, R.; Suli-Vargha, H.; Libert, A.; Loir, B.; Botyánszki, J.; Medzihradszky, K.; Ghanem, G. Receptor-mediated cyotoxicity of $\alpha$-MSH fragments containing melphalan in a human melanoma cell line. Int. J. Cancer 1994, 56, 129-133. [CrossRef]

6. Castrucci, A.M.L.; Hadley, M.E.; Sawyer, T.K.; Wilkes, B.C.; Al-Obeidi, F.; Staples, D.J.; De Vaux, A.E.D.E.; Dym, O.; Hintz, M.F.; Riehm, J.P.; et al. $\alpha$-Melanotropin: The Minimal Active Sequence in the Lizard Skin Bioassay. Gen. Comp. Endocrinol. 1989, 163, 157-163. [CrossRef]

7. Orbán, E.; Mezo, G.; Schlage, P.; Csík, G.; Kulić, Ž.; Ansorge, P.; Fellinger, E.; Möller, H.M.; Manea, M. In vitro degradation and antitumor activity of oxime bond-linked daunorubicin-GnRH-III bioconjugates and DNA-binding properties of daunorubicinamino acid metabolites. Amino Acids 2011, 41, 469-483. [CrossRef] 
8. Miklán, Z.; Orbán, E.; Csík, G.; Schlosser, G.; Magyar, A.; Hudecz, F. New daunomycin-oligoarginine conjugates: Synthesis, characterization, and effect on human leukemia and human hepatoma cells. Biopolymers 2009, 92, 489-501. [CrossRef] [PubMed]

9. Orbán, E.; Manea, M.; Marquadt, A.; Bánóczi, Z.; Csik, G.; Fellinger, E.; Bõsze, S.; Hudecz, F. A new daunomycin-peptide conjugate: Synthesis, characterization and the effect on the protein expression profile of HL-60 cells in vitro. Bioconjug. Chem. 2011, 22, 2154-2165. [CrossRef] [PubMed]

10. Kiss, K.; Biri-Kovács, B.; Szabó, R.; Ranđelović, I.; Enyedi, K.N.; Schlosser, G.; Orosz, Á.; Kapuvári, B.; Tóvári, J.; Mező, G. Sequence modification of heptapeptide selected by phage display as homing device for HT-29 colon cancer cells to improve the anti-tumour activity of drug delivery systems. Eur. J. Med. Chem. 2019, 176, 105-116. [CrossRef] [PubMed]

11. Randelovic, I.; Schuster, S.; Kapuvári, B.; Fossati, G.; Steinkühler, C.; Mezo, G.; Tóvári, J. Improved in vivo anti-tumor and anti-metastatic effect of GnRH-III-daunorubicin analogs on colorectal and breast carcinoma bearing mice. Int. J. Mol. Sci. 2019, 20, 4763. [CrossRef] [PubMed]

12. Tripodi, A.A.P.; Ranđelović, I.; Biri-Kovács, B.; Szeder, B.; Mező, G.; Tóvári, J. In Vivo Tumor Growth Inhibition and Antiangiogenic Effect of Cyclic NGR Peptide-Daunorubicin Conjugates Developed for Targeted Drug Delivery. Pathol. Oncol. Res. 2019, 26, 1879-1892. [CrossRef] [PubMed]

13. Berkowitz, S.A.; Engen, J.R.; Mazzeo, J.R.; Jones, G.B. Analytical tools for characterizing biopharmaceuticals and the implications for biosimilars. Nat. Rev. Drug Discov. 2012, 11, 527-540. [CrossRef]

14. Pethő, L.; Mező, G.; Schlosser, G. Overcharging Effect in Electrospray Ionization Mass Spectra of Daunomycin-Tuftsin Bioconjugates. Molecules 2019, 24, 2981. [CrossRef]

15. Al-Majidi, M.; Szabó, D.; Dókus, L.; Steckel, A.; Mező, G.; Schlosser, G. Energy-resolved HCD fragmentation of daunorubicinpeptide conjugates. J. Mass Spectrom. 2020, 55, e4641. [CrossRef] [PubMed]

16. Sleno, L.; Campagna-Slater, V.; Volmer, D.A. Dissociation reactions of protonated anthracycline antibiotics following electrospray ionization-tandem mass spectrometry. Int. J. Mass Spectrom. 2006, 255-256, 130-138. [CrossRef]

17. Tripodi, A.A.P.; Tóth, S.; Enyedi, K.N.; Schlosser, G.; Szakács, G.; Mező, G. Development of novel cyclic NGR peptideDaunomycin conjugates with dual targeting property. Beilstein J. Org. Chem. 2018, 14, 911-918. [CrossRef]

18. Schuster, S.; Biri-Kovács, B.; Szeder, B.; Buday, L.; Gardi, J.; Szabó, Z.; Halmos, G.; Mező, G. Enhanced In Vitro Antitumor Activity of GnRH-III-Daunorubicin Bioconjugates Influenced by Sequence Modification. Pharmaceutics 2018, 10, 223. [CrossRef] [PubMed]

19. Dókus, L.E.; Lajkó, E.; Ranđelović, I.; Mező, D.; Schlosser, G.; Kőhidai, L.; Tóvári, J.; Mező, G. Phage Display-Based Homing Peptide-Daunomycin Conjugates for Selective Drug Targeting to PANC-1 Pancreatic Cancer. Pharmaceutics 2020, $12,576$. [CrossRef] [PubMed]

20. Syka, J.E.P.; Coon, J.J.; Schroeder, M.J.; Shabanowitz, J.; Hunt, D.F. Peptide and protein sequence analysis by electron transfer dissociation mass spectrometry. Proc. Natl. Acad. Sci. USA 2004, 101, 9528-9533. [CrossRef] [PubMed]

21. Frese, C.K.; Altelaar, A.F.M.; Van Den Toorn, H.; Nolting, D.; Griep-Raming, J.; Heck, A.J.R.; Mohammed, S. Toward full peptide sequence coverage by dual fragmentation combining electron-transfer and higher-energy collision dissociation tandem mass spectrometry. Anal. Chem. 2012, 84, 9668-9673. [CrossRef] [PubMed]

22. Medzihradszky, K.F.; Campbell, J.M.; Baldwin, M.A.; Falick, A.M.; Juhasz, P.; Vestal, M.L.; Burlingame, A.L. The Characteristics of Peptide Collision-Induced Dissociation Using a High-Performance MALDI-TOF/TOF Tandem Mass Spectrometer. Anal. Chem. 2000, 72, 552-558. [CrossRef] [PubMed]

23. Szabó, I.; Manea, M.; Orbán, E.; Csámpai, A.; Bősze, S.; Szabó, R.; Tejeda, M.; Gaál, D.; Kapuvári, B.; Przybylski, M.; et al. Development of an oxime bond containing daunorubicin-gonadotropin-releasing hormone-III conjugate as a potential anticancer drug. Bioconjug. Chem. 2009, 20, 656-665. [CrossRef] [PubMed]

24. Steckel, A.; Schlosser, G. An Organic Chemist's Guide to Electrospray Mass Spectrometric Structure Elucidation. Molecules 2019, 24, 611. [CrossRef]

25. Monneret, C.; Sellier, N. Desorption chemical ionization mass spectrometry of anthracyclines and of trisaccharides related to aclacinomycin A and marcellomycin. Biol. Mass Spectrom. 1986, 13, 319-326. [CrossRef] [PubMed]

26. Dongré, A.R.; Jones, J.L.; Somogyi, Á.; Wysocki, V.H. Influence of Peptide Composition, Gas-Phase Basicity, and Chemical Modification on Fragmentation Efficiency: Evidence for the Mobile Proton Model. J. Am. Chem. Soc. 1996, 118, 8365-8374. [CrossRef]

27. Good, D.M.; Wirtala, M.; McAlister, G.C.; Coon, J.J. Performance characteristics of electron transfer dissociation mass spectrometry. Mol. Cell. Proteom. 2007, 6, 1942-1951. [CrossRef] [PubMed]

28. Mikesh, L.M.; Ueberheide, B.; Chi, A.; Coon, J.J.; Syka, J.E.P.; Shabanowitz, J.; Hunt, D.F. The utility of ETD mass spectrometry in proteomic analysis. Biochim. Biophys. Acta 2006, 1764, 1811-1822. [CrossRef] [PubMed]

29. Sohn, C.H.; Chung, C.K.; Yin, S.; Ramachandran, P.; Loo, J.A.; Beauchamp, J.L. Probing the mechanism of electron capture and electron transfer dissociation using tags with variable electron affinity. J. Am. Chem. Soc. 2009, 131, 5444-5459. [CrossRef] [PubMed]

30. Jones, A.W.; Mikhailov, V.A.; Iniesta, J.; Cooper, H.J. Electron Capture Dissociation Mass Spectrometry of Tyrosine Nitrated Peptides. J. Am. Soc. Mass Spectrom. 2010, 21, 268-277. [CrossRef] [PubMed]

31. Guo, J.; Prokai, L. Conversion of 3-nitrotyrosine to 3-aminotyrosine residues facilitates mapping of tyrosine nitration in proteins by electrospray ionization-tandem mass spectrometry using electron capture dissociation. J. Mass Spectrom. 2012, 47, 1601-1611. [CrossRef] [PubMed] 
32. Heinis, T.; Chowdhury, S.; Scott, S.L.; Kebarle, P. Electron affinities of benzo-, naphtho-, and anthraquinones determined from gas-phase equilibria measurements. J. Am. Chem. Soc. 1988, 110, 400-407. [CrossRef]

33. Smith, R.G. Characterization of Anthracycline Antibiotics by Desorption Chemical Ionization Mass Spectrometry. Anal. Chem. 1982, 54, 2006-2008. [CrossRef]

34. Bachur, N.R. Anthracycline antibiotic pharmacology and metabolism. Cancer Treat. Rep. 1979, 63, 817-820. [PubMed]

35. Steckel, A.; Uray, K.; Kalló, G.; Csosz, É.; Schlosser, G. Investigation of Neutral Losses and the Citrulline Effect for Modified H4 N-Terminal Pentapeptides. J. Am. Soc. Mass Spectrom. 2020, 31, 565-573. [CrossRef]

36. Yu, Q.; Wang, B.; Chen, Z.; Urabe, G.; Glover, M.S.; Shi, X.; Guo, L.; Kent, K.C.; Li, L. Electron-Transfer/Higher-Energy Collision Dissociation (EThcD)-Enabled Intact Glycopeptide/Glycoproteome Characterization. J. Am. Soc. Mass Spectrom. 2017, 28, 1751-1764. [CrossRef] [PubMed]

37. Frese, C.K.; Zhou, H.; Taus, T.; Altelaar, A.F.M.; Mechtler, K.; Heck, A.J.R.; Mohammed, S. Unambiguous phosphosite localization using electron-transfer/higher-energy collision dissociation (EThcD). J. Proteome Res. 2013, 12, 1520-1525. [CrossRef] [PubMed]

38. Yergey, A.L.; Coorssen, J.R.; Backlund, P.S.; Blank, P.S.; Humphrey, G.A.; Zimmerberg, J.; Campbell, J.M.; Vestal, M.L. De Novo Sequencing of Peptides using MALDI/TOF-TOF. J. Am. Soc. Mass Spectrom. 2002, 13, 784-791. [CrossRef]

39. Suckau, D.; Resemann, A.; Schuerenberg, M.; Hufnagel, P.; Franzen, J.; Holle, A. A novel MALDI LIFT-TOF/TOF mass spectrometer for proteomics. Anal. Bioanal. Chem. 2003, 376, 952-965. [CrossRef]

40. Demeure, K.; Gabelica, V.; De Pauw, E.A. New advances in the understanding of the in-source decay fragmentation of peptides in MALDI-TOF-MS. J. Am. Soc. Mass Spectrom. 2010, 21, 1906-1917. [CrossRef] [PubMed]

41. Köcher, T.; Engström, Å.; Zubarev, R.A. Fragmentation of Peptides in MALDI In-Source Decay Mediated by Hydrogen Radicals. Anal. Chem. 2005, 77, 172-177. [CrossRef] [PubMed]

42. Macht, M.; Asperger, A.; Deininger, S.O. Comparison of laser-induced dissociation and high-energy collision-induced dissociation using matrix-assisted laser desorption/ionization tandem time-of-flight (MALDI-TOF/TOF) for peptide and protein identification. Rapid Commun. Mass Spectrom. 2004, 18, 2093-2105. [CrossRef] [PubMed]

43. Khatun, J.; Ramkissoon, K.; Giddings, M.C. Fragmentation characteristics of collision-induced dissociation in MALDI TOF/TOF mass spectrometry. Anal. Chem. 2007, 79, 3032-3040. [CrossRef] [PubMed]

44. Demeule, M.; Régina, A.; Ché, C.; Poirier, J.; Nguyen, T.; Gabathuler, R.; Castaigne, J.-P.; Béliveau, R. Identification and Design of Peptides as a New Drug Delivery System for the Brain. J. Pharmacol. Exp. Ther. 2008, 324, 1064-1072. [CrossRef] [PubMed]

45. Strohalm, M.; Hassman, M.; Kosata, B.; Kodicek, M. mMass data miner: An open source alternative for mass spectrometric data analysis. Rapid Commun. Mass Spectrom. 2008, 22, 905-908. [CrossRef] [PubMed] 